\title{
"Literatura" em Rondônia: Regionalismos e Madeirismos
}

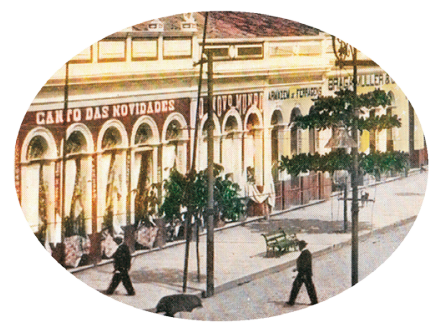

Rafael Ademir Oliveira de Andrade*

"Porto, velho e seguro porto! Chega de trevas, de lassidão. Sentimentos e patrimônios unidos, raízes firmando os pés ao nosso chão"

Identidade, Willian Martins

Não basta os regionalismos nem os cosmopolitismos das moneras: Não basta: precisamos de pontes e, de repente, o gozo de saltar as pontes Manifesto Madeirista

\section{Resumo}

Neste trabalho será iniciada a discussão entre o movimento madeirista e os produtores da chamada arte regionalista em algumas frentes. Primeiro, irei apresentar o que é arte para alguns críticos buscando definir o que seria arte para enfim confrontarmos com o que foi produzido no confronto dos movimentos. A partir daí levantar dados sobre a discussão entre madeiristas e regionalistas, assim, como a definição do que seria cada um dos movimentos. Por fim, realizar análise do confronto principalmente a partir de Bourdieu e seu conceito de campo literário utilizando outros críticos e teóricos como auxiliares. Este trabalho é o primeiro passo para uma interpretação mais profunda que se seguirá.

\footnotetext{
* Graduando em Ciências Sociais na Universidade Federal de Rondônia. Orientando no Centro de Hermenêutica do Presente.
} 
Palavras-chave: Sociologia da literatura; madeirismo; regionalismo.

\begin{abstract}
In this work Will Begin the discussion between the movement madeirista and the producers of the called regionalist art on some fronts. First I will present what is art to some critics seeking to define what is art to finally confront what has been produced in the comparison of movements. Finally, conduct analysis of the confrontation primarily from Bourdieu and his concept of literary field using other literary critics and theorists as assistants. This work is the first step to a deeper interpretation to follow.
\end{abstract}

Keywords: Sociology of literature; madeirismo; regionalism.

\title{
Introdução
}

Neste ensaio apresentarei teorias da sociologia da literatura, história e crítica da literatura brasileira e apontamentos de literatos que me auxiliaram a compor uma opinião sobre a situação atual da Literatura em Rondônia e diferenciá-la em última estância da literatura proposta por alguns destes autores a partir da perspectiva do "regionalismo" e do "madeirismo" enquanto movimentos diacronicamente opostos.

O ponto central deste texto é analisar o campo literário em "Rondônia" a partir do confronto das idéias destes dois movimentos, expressos em seus manifestos e publicações e a partir daí aplicar o conceito de campo e da análise literária adquiridos nas leituras de sociologia e crítica literária.

Como material para análise, utilizaremos material publicado em livros, jornais, sítios da internet, revistas e trabalhos disponíveis na rede mundial de computadores (internet).

A partir destas leituras podemos separar autores de "sociologia," que objetivam realizar uma análise dos campos e os autores de "crítica", envolvidos com a crítica literária ou "engajados" em movimentos literários. Para tal análise comparativa, utilizaremos Liev Tolstoi, Oscar Wilde, Oswald de Andrade, Alberto Lins Caldas, Pierre Bourdieu, Antonio Candido, Theodor Adorno, entre outros.

A definição de Weber do que é sociologia baseia este trabalho enquanto 
sua função. Para Max Weber, sociologia é "uma ciência que pretende entender pela interpretação a ação social para desta maneira explicá-la casualmente no seu desenvolvimento e nos seus efeitos" (WEBER, 2001). A partir disto analisarei de forma crítica o que compreendo enquanto Literatura rondoniense no período em que escrevo este ensaio.

Tive contato com estas teorias no Centro de Hermenêutica do Presente e posteriormente em minha graduação em Ciências Sociais. Em meio a estas atividades realizei a leitura de "clássicos" da literatura e desenvolvi minha atividade enquanto escritor. O hábito de ler e escrever tanto sociologia da literatura quanto literatura e crítica literária fundamentaram o desenvolvimento deste trabalho.

A importância deste trabalho se fundamenta em desvelar, a partir da percepção de um sujeito que não participou do contato entre dos movimentos, realizando uma análise (mais de dez anos após) do impacto dessa discussão para o campo literário em Rondônia.

\section{Debates "Literatura" e literatura}

Esta parte do ensaio tem como objetivo apresentar a diferença entre "literatura" e "Literatura" a partir da diferença apresentada por teóricos da literatura. Essa diferença apresenta o que seria arte e o que seria uma espécie de imitação da arte, a definição do que seriam literatura e "simulacro" de literatura ou "Literatura". Em torno dessas definições gira o confronto entre os movimentos literários aqui discutidos.

Primeiro vamos tentar definir o que é arte a partir de suas relações. Em Adorno (A Arte é Alegre? 1996), apontamos uma dialética da arte entre sua seriedade e sua capacidade de sobreviver aos processos históricos e sociais (como diversão): ela é oposição e diversão ao mesmo tempo: por isso se mantém. Com o advento da modernidade, a arte se tornou uma espécie de "vitamina"para homens cansados (distração, riso, glamour) e representa uma reconciliação com o encanto (visto que o mundo moderno está "desencantado") ou uma afirmação do horror: a diferença entre a "Literatura" de certos escritores e o enfrentamento proposto por Caldas.

O trabalho monográfico de Joesér Álvares da Silva (2003) é apresentado no primeiro capítulo o autor apresenta uma grande variedade de conceitos de 
arte. Vamos citar alguns para demonstrar segundo este trabalho de história da arte como o conceito de arte se modificou (em uma estrutura mais geral). Silva (2003) apresenta o conceito de Gombrich, que é arte como uma técnica a ser dominada expandida até o ponto de apresentar uma visão de mundo.

Citando Read, Silva destaca que "o artista seria basicamente aquele que tem intenção de agradar” (SILVA, 2003). Segundo a percepção marxista, a arte seria uma espécie de manifestação ideológica de classes históricas. Por fim, a arte seria uma expressão única do indivíduo. A discussão do autor sobre o local da arte, sobre os "tipos" de arte durante a "história" compõe uma discussão interessante sobre os lugares da arte e dominação. Eu abordarei esse ponto ao trabalhar com o campo literário para Bourdieu, sobre esta ótica.

A partir desses apontamentos e das leituras realizadas, conceituo "arte" como expressão lógica do indivíduo sobre a influência de "forças" sociais. Entretanto, o relacionamento com essas forças é o que diferencia o artista do artesão. $\mathrm{O}$ artista seria o indivíduo que além da sociedade, da nacionalidade, da religião e de outros discursos sociais possui a vontade (ou a fome) de criar. O artista é egoísta ao ponto de desejar fazer algo único que não só supere o que já foi feito, mas vá de encontro com o esperado. Nessa vontade de "criar" existem pontos técnicos e forças envolvidas.

Quanto à técnica, é preciso dominar sua própria e conhecer as técnicas já exploradas (arte é algo além). Enquanto "forças", entendo por explorar energias (experiências ou sentimentos) que estão presentes na camada mais visceral da vida, as mesmas forças que estão presentes em A Ilíada de Homero quanto em A Metamorfose de Kafka, vida.

Enquanto o simulacro de arte pode ser apontado como o oposto do que é arte. O "artesão" é aquele que transforma sua produção em mercadoria, que agrada ao público, escreve como um diário ou uma criança faz. É o que escreve em favor daquilo que é construído para limitar a vida, os grandes construtos castradores.

Para Caldas, a diferença entre simulacro de arte e arte é definida a partir de oposições similares (até certo ponto) com os apontamentos de Tolstoi. A Literatura é a palavra disciplinada, produção do escritor, que se baseia na reprodução do que já foi feito, do mesmo enquanto a literatura é a produção do "libertino", que deixa passar a literatura, "simplesmente para seu gozo e 
para quem quiser ouvir" (CALDAS, 2001). O mesmo pode ser dito do Poeta e do poeta, o Poeta só consegue reproduzir e não entende o poeta.

Liev Tolstoi afirma em "O que é arte?” (2003) que com maior frequência, a arte tem sido substituída por simulacros, por imitações, cópias, (artesanato, diria Caldas) e neste contexto, tece a distinção entre arte popular, feita pelo homem do povo, que experimentou algum sentimento forte e deseja transmitir ao outro e a arte dos ricos, que é apenas diversão para as classes privilegiadas (não podemos esquecer a vida de Tolstoi, de seu nascimento nobre e da sua convergência para a "causa" dos pobres), (a arte alegre de Adorno). A arte não pode ser encomendada, deve brotar por si mesma. Assim, as classes privilegiadas buscaram produzir algo que se parece com arte, usando certos procedimentos para tal ofício:

Empréstimo (1) usa obras de arte do passado (ou pedaços) e, com certas adaptações, fazem parecer novas (2) Imitação do real, descrever os mínimos detalhes - "como método, o realismo é um fracasso total" dizia Wilde - (3) Surpresa, descrevem com detalhes sentimentos exteriores, produz "estado de espírito" para preencher o vazio de experiências da obra, usa recursos como a descrição do podre, da carne dilacerada (4) Interesse, associa a obra a um elemento de interesse intelectual ou mistério, chamando "atenção" de certos leitores, que pensam estar lendo arte.

Concordando com Tolstoi, Caldas (2001) aponta que qualquer forma de arte, em especial no século XX gera um “artesão ingênuo que pensa que aquilo que faz é arte. Ao mesmo tempo cria um público ingênuo (...) É essa dupla quem move o "mundo da arte" (2001, p. 2), que gera o consumo e a mercadoria da arte, simulacros convencionais e agradáveis. Assim como Tolstoi, Caldas afirma sobre o simulacro de arte:

\footnotetext{
"Nascendo e crescendo com uma arte que parece fácil: simples coisa de criança: qualquer um faz: "é a minha forma de ver": o artesão inicia um exercício aleatório que ele mesmo e seu nascente público chamará de música, pintura, escultura, poesia. Como se parece com o já feito, se torna também da mesma natureza daquilo com que se parece" (CALDAS, 2001, p. 2).
}

Essa forma de arte sem preocupação de enfrentar se baseia na 
"ignorância" e do desconhecimento das pessoas sobre as produções anteriores, assim como aponta em seu ponto (1).

Em contraposição a estes pontos, Van Loon, afirma que a sensibilidade artística "depende do conhecimento, mesmo rudimentar, de técnicas, dados biográficos e histórias, que atraem o leigo para o universo da arte”, ou seja, emprestar sentimentos de outros é uma forma de criar arte enquanto Tolstoi afirma que ao fazê-lo, o artista está criando simulacros de arte.

Uma obra baseada em "empréstimos" (fragmentos de outras obras, do real, de recursos nervosos, aspectos de interesse intelectual) não pode ser considerada uma verdadeira impressão artística, pois falta técnica para expressar o sentimento experimentado pelo artista. Arte "é contaminar os outros daquilo que sentimos".

Oscar Wilde vai concordar com Tolstoi ao debater sobre a decadência da arte, da ciência e do prazer social da mentira. Para o inglês, os historiadores antigos nos ofereceram ficção encantadora sob forma de fatos, enquanto os romancistas modernos nos dão fatos enfadonhos em forma de ficção, reclama de narrativas desinteressantes, repletas de detalhes inúteis, sem o sentimento visceral contido em "O Retrato de Dorian Gray".

Tolstoi aponta como principal característica da arte o sentimento experimentado pelo artista, e para que esta "arte verdadeira" seja "feita", o autor aponta elementos: (1) que o autor possua um nível de concepção elevada em relação a sua época; (2) ter experimentado um sentimento marcante, violento; (3) desejo e possibilidade de expressar tal sentimento, experiência; (4) ter talento para uma arte qualquer. Essas condições são raramente reunidas. Mas em Balzac, segundo Baudelaire, tínhamos essas características reunidas ao ponto que em Balzac suas personagens possuíam o mesmo favor que ele tinha pela vida.

Para se criar simulacros de arte é preciso ter apenas talento, algo facilmente reunido (técnicas e procedimentos, uma criança ou um macaco faz este tipo de arte). Exemplos: na poesia, um homem com talento precisa saber utilizar cada palavra em um lugar determinado e dez outras com mais ou menos o mesmo significado. Após aprender a língua e a rima, poderá criar poesias com qualquer tema (até mesmo sobre o nada).

Para escrever simulacros de romances e novelas, é preciso que o artesão saiba reter tudo que vê. Na música, saber agitar os dedos sobre um instrumento 
é considerado o grau supremo da perfeição: o sentimento fica em segundo lugar, basta saber como se fazia música antigamente e aprender a orquestração, isto é, a maneira de usar os efeitos dos instrumentos em uma composição.

Eis as formulas para o sucesso do artesão sobre as classes privilegiadas, a criação da arte imitação e vazia que abraça os ricos. Citando diretamente Tolstoi, "A arte se deturpou a tal ponto em nossa sociedade que a arte ruim passou a ser boa e chegou-se a perder o conceito de arte". Se a arte se dá na manipulação de diferentes sentimentos (porque cada ser humano sente uma experiência ou até mesmo a mesma experiência de forma única), a falsa arte se dá na imitação ou criação de algo vazio, que não representa sociedades, homens, forças.

Essa força (sentimentos, experiências, percepções) que Tolstoi aponta em seu ensaio é encontrada na obra de Knut Hansun, escritor de "Fome", que era filho de pobres, sendo assim um homem do povo com vontade, experiência e técnica para expressar suas dificuldades econômicas.

O mesmo poderíamos dizer sobre "Memórias da Casa dos Mortos" (Dostoievski) e as experiências do autor com a vida nas prisões da Sibéria, a vida exilada no Alasca de London, Kafka que não superou o pai, a doença, as mulheres e sua grandeza o esmagou como um inseto, o ferimento da primeira guerra mundial, o isolamento, os oito anos de prisão resultaram em "Viagem ao fundo da Noite" de Celine, o mar fixou-se ao coração de Conrad em "Lorde Jim" e em "O coração das trevas". Assim por diante, poderíamos citar em muitas obras que não poderiam ser apresentadas com a devida capacidade neste ensaio, o fato é que cada uma merece análises e críticas literárias de muitas perspectivas focadas.

Alberto Lins Caldas em seu livro "Oligarquia das Letras" (2005) nos concede pontos de interpretação. $\mathrm{O}$ autor concorda com Tolstoi ao afirmar que a língua da literatura deve ser "não mais a língua e a gramática do senhor, o português, mas o brasileiro em suas manifestações singulares, cada vez mais nítidas". Assim, se opõe à "Literatura" das classes privilegiadas, uma imitação de arte, feita para divertir, para ter um propósito que pode ser representar o circundante.

\section{"Literatura” em Rondônia: Regionalistas e Madeiristas}


Em dez de janeiro de 1999 era publicada no jornal Alto Madeira o Manifesto Madeirista. Um documento assinado pelos intelectuais e artistas Alberto Lins Caldas, Carlos Moreira, Joesér Álvares, Gláucio Giordanni e Bira Lourenço. O texto do manifesto apresenta uma série de "não bastas" que incluem os limites de uma cidade, de uma região, do regionalismo, do nacionalismo, das lendas (boto, cobra-grande etc.) a sequência de "não bastas" do madeirismo vai de encontro a tudo, inclusive aos madeiristas, quando afirma que se deve ir sempre além por nada ser o suficiente, ser muito pouco. A arte seria o gozo que dissolve o concreto do mundo.

O movimento do "ir além", da superação do regionalismo e do nacionalismo vai de encontro, obviamente, aos artistas e grupos que levam em seu nome os termos "Rondônia, Amazônia ou Brasileiro". Como por exemplo, a Academia Rondoniense de Letras (ACLER) que apresenta em seu sítio virtual sua fundação se deu a partir da união de artistas "de diferentes segmentos da sociedade rondoniense, autores que contribuíram e contribuem para a formação da literatura rondoniense e brasileira" (ACLER, 2010)2.

Convém afirmar que o regionalismo não é uma corrente fundamentada apenas na Academia Rondoniense de Letras, mas pode ser encontrada nas produções individuais, nas festas populares (em seus versos) e nas músicas dos jovens, como por exemplo, o Manifestejo: Manifesto Beradero, que leva o a bandeira de Rondônia como símbolo, beira do rio, boto, cobra, arraia etc. E também é válido afirmar que o movimento Madeirista se transformou sem deixar de existir e o movimento Barranco, formado por estudantes das mais variadas formações, busca a arte pela arte, literatura por ser literatura. Os movimentos se repetem e influenciam nas universidades, mercados, bares e

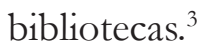

Ao passo em que os regionalistas, como são chamados os artistas que assumem como pontos centrais de suas obras e de suas análises características locais ou regionais escrevem sobre o local, seus fatos históricos, seus heróis e suas preocupações, os madeiristas se propuseram a escrever por escrever, serem artistas pairando sobre as águas, "deixar passar" a arte que seria, "movimento intenso para um além do inexistente" (CALDAS, 2001). O madeirismo não visa fundação de uma arte genuinamente de Rondônia, mas de uma arte sem fronteiras, sem locais. Daí o "conflito de ideias". 
O caráter regionalista da maioria das produções artísticas em Rondônia pode ser considerado herança do pensamento dos modernistas e em especial, dos manifestos de Oswald de Andrade. Esta relação, mesmo que inconsciente faz parte de um processo apontado por Tolstoi e já citado neste trabalho. O "Artista" concebe uma expressão com resquícios do passado e acredita (assim como o público) que está fazendo algo novo.

No Manifesto Pau-Brasil, o modernista afirma que "Ser regional e puro em sua época" (A Utopia Antropofágica, 1990), esta era a alternativa de Oswald para se fazer uma Literatura brasileira. Na Literatura de Oswald de Andrade, analisamos a presença de sua vontade política e estética de modernizar as artes brasileiras com o intuito de formar uma "arte genuinamente brasileira", a partir desta perspectiva, o contato do autor com a intelectualidade europeia, o processo de modernização, a Primeira Guerra Mundial e a quebra da bolsa de valores de 1929 marcaram as escolhas políticas do autor.

Concordo com a expressão de Oswald quando procura esvaziar a "Literatura" brasileira da visão do "branco" que dominou politicamente os selvagens. Ao "eruditarmos tudo", esquecemos de ser brasileiros em nossas manifestações artísticas. Ao fundamentar a poesia Pau-Brasil de exportação, Oswald fundamenta uma literatura que abrangeria o mundial, sendo do brasileiro sem ser presa aos dogmas do que é ser Brasil e contra o parnasianismo, contra a "máquina de fazer versos".

Este manifesto invoca o que é "brasileiro" (e Oswald esquece que além de sua França, existem muitos "Brasis") para se desvincular da produção Europeia dominante. Neste momento é uma invocação válida, mas no momento em que nos encontramos, é válido fugir do regionalismo invocado para desenvolver uma literatura do mundo, ou melhor, literatura da literatura segundo o Madeirismo, que afirma: "Não basta Macunaíma ou Miramar: pouca canibalidade, muita imitação e respeito" (SILVA \& CALDAS \& MOREIRA, 2000, p. 11), referências a obras dos modernistas Oswald e Mário de Andrade.

A indicação "contra o douto" presente no manifesto Pau-Brasil apresenta uma visão que reverbera na construção literária em Rondônia. "Contra o douto" e "Ser regional" representam a produção literária ao ponto que a temática regional e voltada para o que é "daqui” em contraposição clássica ao que é "de fora" é a base para uma parte considerável da produção rondoniense 
como podemos perceber em "O Guaporé" (OLIVEIRA, 2009), "O Barco do Encante” (AMORIM, 2010), Novos Poemas de Amor (ALBINO, 2010) e das produções vinculadas à Academia Rondoniense de Letras (ACLER).

Afirmar que estes e outros autores se utilizam da temática regionalista não é afirmar uma "falta de erudição" dos mesmos, mas uma "escolha" (destaco a variação deste termo, pois a escolha de um tema possui variantes numerosas que não serão debatidas neste momento) temática que se contrapõe a proposta madeirista. Afirmar a falta de "refinamento" cultural dos mesmos partiria de dados que não possuo e acredito que não cabe a este ensaio debater.

O texto de Silva (2000) afirma "Que a questão do regionalismo é vencida - não há o que discutir senão dentro dele. Todos os que aqui desenvolvem a sua arte, foram e/ou são influenciados por ele, isso é inegável. Ponto vencido." (SILVA, 2000). Para ele, os "não bastas" do manifesto Madeirista encontrou eco na Itália e que a arte a partir deste deve ser encarada como um movimento "para frente" que rompa os limites da região e do local.

Em outras palavras, para o autor o século vinte e um em que "fazem arte" madeiristas e regionalistas "pede mais que isso. A contemporaneidade transcende os limites tradicionais, absorve os suportes consagrados (...)" (SILVA, 2000).

Caldas em "Notas sobre literatura e arte" (2001) afirma que a arte "não vem da realidade circundante: a arte vem das entranhas (...), e isso não é provinciano, não é de uma rua, de uma casa, de um barzinho" ao passo que a poesia de Magalhães ${ }^{4}$ afirma Queremos, Porto Velho, que tu cresças Que sejas linda, que tenhas futuro.

Existem regionalismos e regionalismos. O regionalismo descrito pelo crítico Nelson Werneck Sodré se funda a partir de zonas profundas onde o romantismo não poderia fornecer certos elementos característicos. Outro conceito para regionalismo afirma que: "reduz o regionalismo a sinônimo de localismo literário, a literatura regional não passando da exploração e exposição do pitoresco, das formas típicas, do colorido especial das regiões" (SODRÉ, p. 404, 1982).

Ao ponto que o regionalismo concede o sentimento (ou força, cria) de pertencimento à terra, coloca o ambiente acima das criaturas, como se este fosse um ente superior, o regionalismo: 
"entende o indivíduo apenas como síntese do meio a que pertence, e na medida em que se desintegra da humanidade (...) busca nas personagens, não o que encerram de pessoal e relativamente livre, mas o que as liga ao seu ambiente, isolando-as de todas as criaturas estranhas àquele" (SODRÉ, p. 404, 1982).

E esta é uma crítica fundamental do madeirismo ao regionalismo em Rondônia. Em Madeirismo: Ensaios Libertinos, Caldas afirma que pintar uma mulher, um boto, uma igreja não faz de ninguém um regionalista, o regionalismo (neste contexto apresentado) "é a pouca ambição de ser, em ano ser senão cópia chinfrim de pouco ou nada, pastiche de estereótipos" (CALDAS, 2000, p. 67), é olhar, fazer, se dizer fazer arte e não fazer nada, "um silêncio mortal diante do nada", é a escolha de falar do local e se esconder de confrontar o que há de mais visceral, o indivíduo.

Para o crítico Sodré (1982), o regionalismo possui certas limitações. Destacamos as seguintes: a fascinação servil pelo meio geográfico, a crença de que a descrição de um local descreveria os indivíduos que ali se encontram, sendo estes influenciados por certas peculiaridades de raça e tradição, distinguir as personagens pelo modo de falar (influência do naturalismo ${ }^{6}$ ), a apresentação de verbetes únicos da região, exigindo a presença de um vocabulário para explicação de tais termos, muitas vezes excessivos como no conto "Trez̧entas Onças" de Simões Lopes Neto ${ }^{7}$. Esta forma de se representar a fala do "caipira" prende-se a um conceito inaceitável de arte, como afirma Sodré (p. 419, 1982).

Entretanto, este mesmo autor afirma que o regionalismo contribuiu para a formação de uma literatura nacional e de tipos nacionais, por exemplo, a literatura em Rondônia invoca o soldado da borracha, o índio (o índio, não o indígena), o caboclo, o pescador, o migrante nordestino, etc. Para os madeiristas, a criação de uma literatura nacional é uma das formas da criação de uma arte servil. O Madeirismo não é "um movimento sequer brasileiro" (CALDAS, 2000, p. 53), a proposta do madeirismo é criar contra e além, arte por libertinagem, contra o Brasil.

Para finalizar a ligação com Sodré, o crítico afirma que o regionalismo apresentou em seu ápice a sua maior deficiência, a realidade não está apenas na superfície, o meio aparece pelas personagens e não o contrário. A seca, a cheia dos rios, a vida no campo não é percebida da mesma forma por todos os indivíduos de uma determinada região, o seringueiro percebe a época das 
chuvas de forma diferente do navegador de rios. E aqui voltamos para o que é arte para Tolstoi: a arte não copia o real ou o passado (como aponta o saudosismo regional), arte é o retrato do indivíduo e suas experiências marcantes.

A grande falha em descrever a realidade se encontra em Jeca Tatu de Monteiro Lobato ${ }^{7}$ o tipo (caipira) condenou a personagem. Este é o esgotamento do regionalismo.

De acordo com estas leituras posso afirmar que as publicações e manifestações dos dois movimentos apontam para uma divergência gigantesca entre os mesmos. Esta diferença foi percebida pelos participantes na época em foi publicado o manifesto Madeirista e com a leitura desta parte do trabalho, o leitor poderá compreender a tensão (pelo menos em parte) que se criou com a publicação do manifesto e suas respostas.

\section{Sociologia, "Literatura” e Campos}

A sociologia da literatura não fundamenta a literatura como criação de um homem singular e a reivindicação da leitura (interpretação) dos textos literários como apenas literária. Esta afirmação busca confundir a análise científica dos livros e da leitura, pois, as ciências (sociais) teriam um "pacto" (uma relação estrita) com os números, os dados, diminuindo assim o caráter singular da criação literária. O que de fato não ocorre, a extensa produção da sociologia da literatura afirma que a sociologia se relaciona com as artes e pode interpretá-la de forma concisa.

Para Antonio Candido, sociólogo brasileiro, compreende que a área de atuação da sociologia da literatura como: "pesquisar a voga de um livro, a preferência estatística por um gênero, o gosto das classes, a origem social dos autores, a relação entre as obras e as ideias, a influencia da organização social, econômica e política, etc" (CANDIDO, 1985, p. 4).

Pierre Bourdieu busca firmar em seu discurso a relação entre literatura e sociedade. Compreendemos a criação literária como um produto da ação humana, formada e tomada conhecida a partir das relações de poder dentro dos campos sociais. Uma análise sociológica da criação literária busca a análise cientifica das condições sociais na produção e recepção, das relações sociais do autor e "não visa dar a ver, ou a sentir, mas construir sistemas de relação inteligíveis capaz de explicar os dados sensíveis” (BOURDIEU, 1992, p. 14) 
presentes na criação literária.

Compreender o campo social literário, das crenças, dos jogos de poder (simbólicos ou materiais) que se estabelecem no mesmo não define uma redução da criação literária e, sim, uma nova visão da mesma, nas palavras de Bourdieu (p. 16, 1992) "É simplesmente olhar as coisas de frente e vê-las como são. Este discurso inicial proposto pelo autor afirma que as produções literárias (e artísticas em geral) não são objetos apenas da interpretação literária, mas podem ser interpretadas sociologicamente, assim pode ser definida a função da sociologia da literatura.

O conceito de campo social afirma que o mesmo é definido por espaço com postos estruturados e as propriedades do campo dependem das posições que se formam no interior destes. O campo social é definido pelo apontamento dos objetos de disputa e interesses e não é percebido (ou não possui o capital simbólico desejado) para quem não participa do campo. Assim, o campo "Literário ou literário" ou das produções artísticas Rondoniense seria formado por escritores, produtores, músicos, críticos, jornalistas que tem como objeto em comum a disposição para os outros campos o reconhecimento do que é arte e do que não é.

Todos os participantes do campo reconhecem, segundo Bourdieu, que a disputa ocorre e que posições são ocupadas. Os reconhecimentos destas disputas e dos interesses são vitais para a manutenção do campo, em outras palavras, os congressos, manifestos, shows, sítios na rede, academias, grupos de pesquisa, são formas de disputa que mantém o campo funcionando. Em outras palavras, deve existir um objeto de disputa (o reconhecimento do que é arte), indivíduos que desejem disputar o objeto (artistas, movimentos) e o conhecimento das leis do "jogo", "o habitus".

Nesta análise vamos entender os movimentos citados como agentes, sem adentrar na questão dos indivíduos que ocupavam posições individualmente visto que o objetivo deste trabalho é confrontar os dois movimentos dentro do campo literário.

A estrutura dos campos é mantida na relação de força entre os agentes engajados na distribuição de capital específico, o capital disputado dentro do campo. Como dito anteriormente, a disputa tem como objetivo o monopólio da autoridade específica, válida dentro do campo. Os detentores desde monopólio tendem conservar o domínio enquanto os recém-chegados tendem a estratégias 
de mudança, sob a ameaça de serem expulsos. $\mathrm{Na}$ disputa entre madeirismo e regionalismo, este detinha o monopólio do capital específico, afirmando o que é arte e principalmente, arte de Rondônia, a partir de suas definições do que é arte e seus conflitos para que os sujeitos ocupassem posições dentro do campo aconteciam entre os regionalistas e eventuais participantes engajados.

A partir da publicação do manifesto Madeirista, temos a disputa entre os dois grupos pelo poder de afirmar o que é arte ou se "existe arte" sendo produzida em Rondônia. Esta disputa se materializou em publicações dos grupos envolvidos sendo uma das destacadas a questão da exposição do "Coletivo Madeirista" que foi vetada pela casa de Cultura Ivan Marrocos devido seu desrespeito ao espaço público e a "classe artística". Neste momento de conflito, o nome do "movimento madeirista" foi invocado muitas vezes para invocar a posição de "baderneiros e contra a arte local". O conflito dos grupos é representado por este evento que ocorreu em 2007, mais recente que as discussões em torno do manifesto.

Cada movimento desse jogo, todo conhecimento acumulado de suas regras e movimentos são conhecidos e representados pelos seus participantes e na crença particular de cada um e todos os indivíduos tem interesse em conversar o jogo desta forma. Em outras palavras, tanto regionalistas quando madeiristas concedem certo valor à arte ou acreditam estar fazendo arte, na existência da arte e suas ligações.

O campo social literário é formado por produtores, editores, críticos, etc. É caracterizado por baixo nível de codificação e alta permeabilidade, com grande diversidade de postos, por este motivo, atrai e recebe em seu meio participantes com propriedades e convicções diferentes entre si.

Em outras palavras, o campo literário é composto por indivíduos das mais variadas classes e profissões, mas eles acreditam no jogo do campo: no valor da arte, no que é arte a aposta central do jogo do campo literário visa o monopólio de consagração de grandes produtores ou produtos, o monopólio da legitimidade da produção literária. A luta por este monopólio contribui para a reprodução contínua do jogo. As hierarquias ou fronteiras que são defendidas nesta disputa são, em última estância, a defesa do próprio campo.

O campo literário deve ser o único com aval, com capacitação para legitimar o que é produção literária assim como a classificação desta. Em suma, a consagração das obras e produtores é delimitada pelo próprio campo. E é por este capital específico que os movimentos madeirista e regionalista 
entraram em confronto: a arte regionalista está focada no local enquanto a arte madeirista é um movimento além, sem fronteira, focada no indivíduo e suas vicissitudes.

Este poder simbólico influenciará a outros campos, principalmente os que receberão estas produções, assim como as posições ocupadas pelos participantes do campo da produção literária. Além desta característica, o campo social é o produtor do valor das obras de arte, que reproduz um sistema de crenças do valor desta produção e a crença no poder criador do artista, "o valor de uma obra é dada por indivíduos capacitados, ou seja, que também participem do campo das produções ou similares, instituições responsáveis pela crença no valor da arte" (BOURDIEU, 1996, p. 259).

A análise do campo social das produções culturais tratada por Bourdieu aponta que interpretação da ciência das obras culturais supõe três operações ligadas à realidade social que representam. A primeira operação consiste em analisar a posição do campo literário em relação ao campo do poder e a evolução de sua autonomia em relação a este. Esta operação nos permite uma argumentação em relação aos movimentos em confronto aqui apresentados.

Enquanto o regionalismo se funda como "arte original" do território, sendo propagado na mídia impressa, online e televisiva, nos "locais de cultura" (casa de cultura, mercados culturais, teatros, eventos regionais) e possui certa relação de dependência com o campo do poder, o madeirismo mantém outras relações com esse campo. Não ocupa os mesmos "locais de cultura", mas se centrou nas escolas e na Universidade Federal de Rondônia, hoje em dia é possível ver madeiristas (movimento e coletivo) ocupando exposições ou shows nesses "locais de cultura", mas sua posição subversiva e a procura pela arte "sempre a frente" é perceptível.

O madeirismo se posiciona como independente em relação ao campo de poder, pelo menos mais independente. Esta relação se funda em seu próprio matiz ideológico: que é contra o Estado, pela "arte crua" e balzaquiana, flutuando acima da sociedade. Estas posições do regionalismo e do madeirismo influenciam na forma que as produções são propagadas. As produções regionais ocupam maior destaque dentro da região ou como representantes da região para o grande público enquanto a literatura madeirista, sem apoio do Estado, se propaga nas redes de comunicação dos seus participantes e nos simpatizantes, dentro e fora da região. 
A segunda operação consiste na análise da estrutura interna do campo, suas leis de funcionamento e de transformação, relação de poder entre membros e seus grupos. Destacamos nesta segunda operação que no período anterior à publicação do "Manifesto Madeirista" as produções do regionalismo se difundiam normalmente em suas relações, sendo organizados por clubes, academias etc.

A academia Rondoniense de Letras foi fundada em 1986. Entretanto, ao realizar a leitura de Badra (1987), tive contato com outro panorama da literatura na ainda Unidade Federativa de Rondônia. Segundo este autor, na década de setenta do século vinte, ocorreu uma migração sem precedentes para o território onde a população quase quintuplicou em dez anos. Com este intenso fluxo, "os nativos passaram a representar a camada minoritária da população” (BADRA, 1987, p. 9). Essa característica dificultaria a afirmação do que seria uma literatura de Rondônia.

Segundo o autor, problemática da literatura em Rondônia gira em torno de dois parâmetros: a) a necessidade de uma integração dos autores à comunidade rondoniense, excluindo os de "passagem acidental" (o que excluiria aqueles que não tivessem interesse no que ocorre na comunidade regional, como os madeiristas) e b) a temática não limitada à vida rondoniense. Para Badra, não escrever sobre temas referentes a Rondônia seria um problema a ser superado pela literatura rondoniense. Nesta frase encontramos o cerne da literatura regionalista do Estado, das respostas ao madeirismo e das publicações que tivemos acesso.

Sobre a poesia de Rondônia, Badra afirma ainda que:

"Embora aparentemente mais fácil, essa poesia
"desestudada", natural, de mensagem compreensível à
primeira leitura, mormente quando desprovida de ritmo
e rima, é, na realidade, a de mais difícil composição, posto
que muito se assemelhe à prosa" (BADRA, 1987, p. 15).

E contra esta poesia desestudada (sem formação), parecida com a prosa (Poesia que conta história, não poesia, onde cada palavra carrega uma força, um mundo) é que se opõe o manifesto madeirista. Badra cita os poetas Ildelfonso de Paula Martins (poema "Natal"), onde demonstra estar em prantos por estar longe da família e de Cristo, o poeta Silvio Persivo da Cunha, cuja obra defende a moral, Gerson Magalhães, afeito à religiosidade, pede vigor a deus 
em "Prece do Ano Novo". Apresenta na prosa rondoniense os nomes de Ari Tupinambá Pena, Vitor Hugo, Matias Mendes, Amizael Gomes, chamando-os de "cronistas dos nossos tempos e das nossas gentes" (BADRA, 1987, p. 23).

Estas estruturas foram abaladas com a publicação do manifesto madeirista, gerando um conjunto de publicações em defesa da produção local (e seus produtores) ou contra as publicações madeiristas. ${ }^{9}$ Nos primeiros dez anos da publicação do manifesto (mais intensamente nos primeiros dois anos) o campo das produções literárias em Rondônia foi modificado por tal confronto.

Por fim, a terceira operação consiste na análise da gênese do "habitus" dos ocupantes das posições, o sistema de disposições, que é fruto da localização dos mesmos dentro das posições do campo. A construção do campo é uma condição para a construção da trajetória social dos indivíduos participantes do mesmo. Em outras palavras, a posição que madeiristas e regionalistas ocupam dentro do campo literário determinam como suas obras serão aceitas, incentivadas ou rechaçadas pelo público, pelas editoras, etc.

O madeirismo, enquanto movimento artístico se caracterizou pelo movimento de alguns agentes engajados no campo literário em direção a estabelecer uma nova relação com o campo do poder e a transformação de certos aspectos do campo literário, o que nos é apresentado em alguns temas contrastes: arte versus artesanato, local versus visceral, Literatura regional e literatura.

O impacto deste movimento sobre o campo literário rondoniense no século XX as relações deste com o campo do poder (e outros), algumas leis de funcionamento (mudança estética, vista no romance Senhor Krauze de Alberto Lins Caldas e nas poesias de Carlos Moreira), a relação de poder entre os membros do campo (criando uma cisão entre os literatos "regionalistas", uma nova discussão intelectual e jornalística). Entendo que este impacto perdurou por pouco tempo, tendo em vista que dez anos após o início do mesmo, quase não existe mais esse debate entre os dois movimentos (que logicamente se transformaram socialmente).

O campo literário é considerado, se confrontado com o poder econômico como um "mundo econômico invertido", os seus participantes têm interesse no desinteresse, provando em muitos casos a autenticidade das obras pelo fato de que essa prática não gera nenhuma remuneração. Entretanto, por mais 
livres que estejam das negociações externas, os escritores são "atravessados pela necessidade dos campos englobantes, a do lucro, econômico ou político" (BOURDIEU, 1996, p. 246).

Temos aqui a apresentação de um conflito interno do campo literário, que geram dois princípios de hierarquização, o heterônomo, que favorece os que dominam o campo de forma econômica e política, e o autônomo que representa a arte pela arte. O conflito entre os que defendem a "arte pura" e os que defendem a "arte burguesa ou comercial" visa impor os limites do campo aos seus próprios interesses. Esses limites conflitantes do campo literário são caracterizados pela dicotomia.

O princípio da hierarquização externa, característica da "arte burguesa" é medido pelo índice de sucesso comercial (literatura comercial) ou de notoriedade social. Já o principio de hierarquização interna, grau de consagração específica, favorece os artistas conhecidos e reconhecidos por seus pares e unicamente por eles, que não atendem à demanda do grande publico, por consequência, característica da "arte pura", arte pela arte (BOURDIEU, 1996). A independência (arte pela arte) ou subordinação (arte comercial) com relação à demanda do grande público e às sujeições do mercado, adesão dos valores de desinteresse, o volume do público, constituem sem dúvida, o indicador mais seguro da posição ocupada no campo.

O que a dicotomia entre arte burguesa, arte comercial ou arte do Estado e a "arte pela arte" representa neste trabalho é que, em primeira estância, a arte regionalista é fundada no princípio da arte burguesa, da arte pelo Estado, sendo vendida largamente em tempos de vestibular para a Universidade Federal, com seus lançamentos públicos, incentivados pelos programas de financiamento do Estado enquanto a literatura madeirista passa por outros aspectos.

Em seu arcabouço ideológico (em seu manifesto, em suas publicações) o madeirismo afirma a sua tendência da "arte pela arte" o que influência nas produções de Cátia Cernov, Joesér Álvares, Carlos Moreira, participantes de grupos orientados pela visão madeirista (ou livre) de arte.

\section{Considerações finais}

A partir de poucos teóricos podemos realizar tal leitura do confronto entre os movimentos aqui citados. Ressaltamos também que o regionalismo ainda não é conhecido como um movimento único; ele apenas perpassa grande 
número das produções do campo literário rondoniense em larga escala. Por esse motivo, o movimento madeirista tenha sido importante: a partir deste podemos perceber uma movimentação do regionalismo e uma espécie de organização. Após este período, voltamos ao momento anterior à publicação do manifesto madeirista: o regionalismo se funda em grande maioria das produções.

Como essa movimentação se deu pode ser uma análise realizada em um trabalho posterior. Este é um artigo introdutório. Cabe relacionar de forma mais estrita os conflitos publicados em jornais e em sítios da rede mundial de computadores assim como a "fala" de produtores envolvidos de ambos os movimentos além do envolvimento de outros teóricos na análise dos dados coletados.

O que pude notar é que antes do movimento madeirista as artes nas Rondônia (se é que existe) era formado por uma grande massa regionalista ou de produtores neutros. O conflito sempre é uma forma transformação, de renovação, destruição e aberturas de novos caminhos para a arte violar.

Sempre além, contra o frio dentro de nós.

\section{Notas}

${ }^{1} \mathrm{O}$ nome "Madeirismo" (como afirmam os autores de Madeirismo: Ensaios Libertinos, EDUFRO, 2000) é uma ironia, um deboche para tudo que é regional. O madeirismo não é um regionalismo, "é palhaçada que quase todo mundo engoliu: não engulam mais: nós somos contra você." (p. 53). Esta citação, como tantas outras, é uma afronta ao regionalismo em Rondônia e marca o confronto entre os dois grupos (ou dos variados grupos em confronto).

${ }^{2}$ No sitio virtual da ACLER tive acesso ao histórico da instituição, palestras e publicações que foram lidas para o desenvolvimento desta análise.

${ }^{3}$ O Manifestejo Manifesto Beradero pode ser encontrado em http://beradelia. blogspot.com/. Este documento foi publicado neste site e foi distribuído na UNIR. Acessado às 11h20min de 17 de Maio de 2011.

${ }^{4}$ Membro da Academia Rondoniense de Letras, ocupante da cadeira número 2. A poesia que faço referencia se chama Porto Velho Ontem e Hoje e está disponível em http://acler.com.br/academicos/19.html, acessado as $11 \mathrm{~h} 11 \mathrm{~min}$ do dia 10 de Maio de 2011.

${ }^{5}$ Que acredita que a personagem será mais bem descrita se certas exteriorizações forem apresentadas, tais como roupas, cotidiano, modo de falar, sendo que este 
último se destacou.

${ }^{6}$ Simões Lopes Neto, escritor regionalista nascido no Rio Grande do Sul, segundo a crítica, uma importante figura do pré-modernismo. Apesar de o crítico Douglas Tufano (Do Romantismo ao Modernismo, 2005) apontá-lo como um autor que busca ver o humano por baixo da essência regionalista, o que vemos no conto Trezentas Onças é um esforço para descrever o vaqueiro, as condições climáticas, as relações sociais de poder da região etc. tudo isto regado a um extenso vocabulário.

7 Personagem inicialmente conhecido pelo público no livro regionalista de contos "Urupês" de Monteiro Lobato, criador do conhecido mundo de fantasia do "Pica Pau Amarelo".

8 O coletivo Madeirista é formado por "simpatizantes" do movimento Madeirista e tem como objetivo levar a "arte de Rondônia" como tem feito em suas diversas apresentações em muitos lugares do Brasil e fora deste. Fonte: www.rondoniaovivo. com.br/noticias/polemica-cultural-artistas-do-coletivo-madeirista-rebatem-nota-dacasa-da-cuktura-sobre-exposicao/22285. Um dos eventos perceptíveis do coletivo em Rondônia é o "inventário das sombras".

9 Como os textos de José Maria Ortiz de Carvalho, "Madeirismo: Vanguarda ou Ismo?", "Visão Crítica do Madeirismo" de Antônio Serpa do Amaral Filho e "Os Madeiristas" de Zé Katraca. Todos respondidos pelos madeiristas. Estes textos serão analisados em outra oportunidade.

\section{Referências}

ANDRADE, Oswald de. A trilogia do Exílio: I. Alma (1922) - II. A Estrela do Absinto (1927) - III. A Escada Vermelha (1934) / Oswald de Andrade. - São Paulo: Globo, 2003. (Obras Completas de Oswald de Andrade). O aluno de Romance / [crítica] por Mário da Silva Brito - A trilogia do Exílio [crítica] por Sérgio Millet.

- A Utopia Antropofágica. São Paulo: Globo: 1990.

ANDRADE, Rafael Ademir Oliveira de. Literatura da Meia-Noite. Ana Carolina Giorgion (Org.) Casulos da Alma: Antologia de Crônicas. Praia Grande, SP. Literata, 2010.

- Romance e Sociedade: Apontamentos Teóricos. Primeira Versão (UNIR). Edufro, 2010. 
BADRA, Edson Jorge. Literatura em Rondônia. Série Caderno Cultural. Governo do Estado de Rondônia, Secretaria do Estado de Cultura, Esportes e Turismo. Porto Velho, 1987.

BOURDIEU, Pierre. Regras da Arte: Gênese e estrutura do campo literário. São Paulo: Companhia das Letras, 1996.

CALDAS, Alberto Lins. Notas sobre literatura e arte. Porto Velho. Revista Primeira Versão (UNIR). Edufro, 2001.

. Oligarquia das Letras. São Paulo. Terceira Imagem, 2005.

. Que é o Madeirismo. In Madeirismo: Ensaios Libertinos. Caderno de Criação 24, Ano VII, Dezembro, Porto Velho, 2000.

- Madeirismo versus Minhoquismo. In Madeirismo: Ensaios Libertinos. Caderno de Criação 24, Ano VII, Dezembro, Porto Velho, 2000.

CANDIDO, Antonio. Literatura e Sociedade: Estudos de Teoria e História Literária. 7. ed., São Paulo, Editora Nacional, 1985.

IANNI, Octávio. Sociologia e Literatura. In Sociedade e Literatura no Brasil. José Antônio Segatto; Ude Baldan (Orgs). Editora UNESP, São Paulo, 1999.

MENDES, Matias. A Fronteira e seus Heróis. ACLER. Disponível em www. acler.com.br em 29 de maio de 2011, às 10h42min.

NETO, Miguel Leocádio Araújo. A Sociologia da literatura: Origens e Questionamentos. Revista Entrelaces.. Agosto de 2007.

PEREIRA, José Valdir. Discurso de encerramento de mandato Biênio 2008/2009. ACLER. Disponível em www.acler.com.br em 24 de maio de 2011, às $11 \mathrm{~h} 12 \mathrm{~min}$.

SANTOS, Dennis de Oliveira. Sociologia da Literatura. Revista Urutágua. No 14, Dez. 7/ Jan./Fev./Mar./2008 - Quadrimestral - Maringá, ISSN 1519-6178.

SILVA, Joesér Álvares da. Net.Arte: A imanência das redes na história das artes. Trabalho monográfico, História, UNIR, 2003.

Madeirismo na Bienal. In Caderno de Criação, ano VII, $\mathrm{n}^{\circ} 24$, Porto Velho, 2000.

SODRÉ, Nelson Werneck. História da Literatura Brasileira. 7. ed. Difel, São 
Paulo, 1982.

WEBER, Max. Metodologia das Ciências Sociais. São Paulo. Editora Cortez, 2001.

\section{Obras Consultadas}

ALBINO, Pedro. Novos Poemas de Amor. Scortecci. São Paulo, 2010.

ALBINO, Pedro. 69 Poemas de Amor. Scortecci. São Paulo, 1995.

AMORIN, Kátia Fernanda Amorim. O Barco do Encante. Primor Formulários Gráficos. Porto Velho, 2010.

CALDAS, Alberto Lins. Senhor krauze. Revan, Rio de Janeiro, 2009. . Babel. Revan, Rio de Janeiro, 2001.

CERNOV, Cátia. Amazônia em Chamas. Editora Literatura Marginal, Selo do Povo, São Paulo, 2010.

OLIVEIRA, Maria de Fátima Pereira de. O Guaporé. São Carlos. Pedro \& João Editores, EDUFRO, 2009. 